\section{Combined pulmonary fibrosis and emphysema: a distinct underrecognised entity}

\author{
V. Cottin*, H. Nunes\# ${ }^{\#}$ P-Y. Brillet ${ }^{\text {I }}$ P. Delaval ${ }^{+}$, G. Devouassoux ${ }^{\S}$, I. Tillie-Leblond ${ }^{f}$, \\ D. Israel-Biet**, I. Court-Fortune ${ }^{\# \#}$, D. Valeyre ${ }^{\#}$, J-F. Cordier* and the Groupe \\ d'Etude et de Recherche sur les Maladies "Orphelines" Pulmonaires \\ (GERM“'O”P)
}

ABSTRACT: The syndrome resulting from combined pulmonary fibrosis and emphysema has not been comprehensively described.

The current authors conducted a retrospective study of 61 patients with both emphysema of the upper zones and diffuse parenchymal lung disease with fibrosis of the lower zones of the lungs on chest computed tomography.

Patients (all smokers) included 60 males and one female, with a mean age of 65 yrs. Dyspnoea on exertion was present in all patients. Basal crackles were found in $87 \%$ and finger clubbing in $43 \%$. Pulmonary function tests were as follows (mean \pm SD): total lung capacity $88 \% \pm 17$, forced vital capacity (FVC) $88 \% \pm 18$, forced expiratory volume in one second (FEV1) $80 \% \pm 21$ (\% predicted), FEV $1 /$ FVC $69 \% \pm 13$, carbon monoxide diffusion capacity of the lung $37 \% \pm 16$ (\% predicted), carbon monoxide transfer coefficient $46 \% \pm 19$. Pulmonary hypertension was present in $\mathbf{4 7 \%}$ of patients at diagnosis, and $55 \%$ during follow-up. Patients were followed for a mean of $2.1 \pm 2.8$ yrs from diagnosis. Survival was $87.5 \%$ at 2 yrs and $54.6 \%$ at 5 yrs, with a median of 6.1 yrs. The presence of pulmonary hypertension at diagnosis was a critical determinant of prognosis.

The authors hereby individualise the computer tomography-defined syndrome of combined pulmonary fibrosis and emphysema characterised by subnormal spirometry, severe impairment of gas exchange, high prevalence of pulmonary hypertension, and poor survival.

KEYWORDS: Emphysema, interstitial lung disease, pulmonary arterial hypertension, pulmonary fibrosis

담 mphysema and the idiopathic interstitial pneumonias, including idiopathic pulmonary fibrosis (IPF), are entities defined by distinct clinical, functional, radiological, and pathological characteristics. Combined pulmonary fibrosis and emphysema (CPFE) has been mentioned in passing in series of patients with IPF or has been the subject of case reports or short series [1-3], but has not hitherto been specifically studied in a large cohort of patients. The current study provides a detailed analysis of the clinical characteristics of a homogenous group of 61 patients with computer tomography (CT)defined CPFE, thus leading to the individualisation of a characteristic entity, and further shows that the presence of pulmonary arterial hypertenof prognosis in these patients.

\section{PATIENTS AND METHODS}

\section{Case recruitment}

This retrospective multicentre study was conducted by the Groupe d'Etudes et de Recherche sur les Maladies "Orphelines" Pulmonaires (GERM“'O"P), a collaborative group of $>200$ physicians dedicated to the study of rare (socalled "orphan") pulmonary diseases. A letter was sent to all participating physicians of the network asking them to report to the sion (PAH) at diagnosis is a critical determinant
AFFILIATIONS

*Service de Pneumologie, Centre de référence des maladies orphelines pulmonaires, Hôpital Cardiovasculaire et Pneumologique Louis Pradel, Université Claude Bernard, and UMR 754 INRA-ENVL-UCBL, Lyon, and \# Service de pneumologie, and "Service de radiologie, Hôpital Avicenne, Bobigny,

'Dépt de pneumologie et cardiologie, Centre Hospitalier Universitaire de Rennes,

${ }^{5}$ Service de pneumologie, centre hospitalier Lyon Sud, Pierre Bénite, ${ }^{\dagger}$ Service de pneumologie, Centre Hospitalier Universitaire de Lille, ${ }^{*}$ Service de pneumologie et soins intensits, Hôpital européen G.

Pompidou, Paris, and

\#\#Service de pneumologie, Hôpital Nord, Saint-Etienne, France.

CORRESPONDENCE

J-F. Cordier

Groupe d'Etudes et de Recherche sur les Maladies "Orphelines"

Pulmonaires

Hôpital Cardiovasculaire et

Pneumologique Louis Pradel

69677 Lyon (Bron)

France

Fax: 33472357653

E-mail: germop@univ-lyon1.fr

Received:

February 232005

Accepted after revision:

June 292005

European Respiratory Journal

Print ISSN 0903-1936

Online ISSN 1399-3003 
GERM“'O'P registry any case of CPFE encountered between January 1985 and December 2003. The clinical data was then collected retrospectively through a detailed questionnaire that was sent to each participating physician who had reported cases. Data collection ended on July 1, 2004.

\section{Selection of cases}

Cases were acceptable for inclusion if the following criteria were met. 1) Presence of emphysema on CT scan, defined as well-demarcated areas of decreased attenuation in comparison with contiguous normal lung and marginated by a very thin $(<1 \mathrm{~mm})$ or no wall, and/or multiple bullae $(>1 \mathrm{~cm})$ with upper zone predominance. 2) Presence of a diffuse parenchymal lung disease with significant pulmonary fibrosis on CT scan, defined as reticular opacities with peripheral and basal predominance, honeycombing, architectural distortion and/or traction bronchiectasis or bronchiolectasis; focal ground-glass opacities and/or areas of alveolar condensation may be associated but should not be prominent.

Only cases for which a CT scan was available for review were included.

Patients with connective tissue disease at the time of the diagnosis of CFPE were excluded from the study, as well as patients with a diagnosis of other interstitial lung diseases, such as drug-induced interstitial lung disease, pneumoconiosis, hypersensitivity pneumonitis, sarcoidosis, pulmonary histiocytosis, lymphangioleiomyomatosis and eosinophilic pneumonia [4].

\section{Clinical analysis}

The authors reviewed the medical records, pulmonary function tests and laboratory tests at diagnosis and during follow-up.

High-resolution CT (HRCT) scans of the chest were reviewed on films separately by two of the authors without knowledge of the clinical data, with a third analysis when discordant. They were asked to specify whether the CT pattern of the lower lobe abnormalities was typical of IPF, or strongly suggestive of IPF or fibrosing nonspecific interstitial pneumonia [4]. Data were collected for emphysema characteristics and the main interstitial abnormalities, as defined elsewhere [5].

Open lung biopsy, when available, was reviewed according to international criteria [4].

Pulmonary function tests were performed according to the European Respiratory Society guidelines [6]. The alveolararterial oxygen difference $P(\mathrm{~A}-\mathrm{a}), \mathrm{O}_{2}$ while breathing room air was estimated as the difference between alveolar oxygen partial pressure $\left(P A, \mathrm{O}_{2}\right)$ and the partial pressure of oxygen in arterial blood $\left(\mathrm{Pa}_{\mathrm{a}} \mathrm{O}_{2}\right)$, where:

$$
\begin{gathered}
P A, \mathrm{O}_{2}=(\text { mean barometric pressure }[101.3 \mathrm{kPa}]-6.3) \\
\times 0.21-\mathrm{Pa}, \mathrm{CO}_{2} / 0.8
\end{gathered}
$$

$\mathrm{Pa}_{1} \mathrm{CO}_{2}$ is the partial pressure of carbon dioxide in arterial blood.

PAH was defined by a systolic arterial pulmonary pressure $\geqslant 45 \mathrm{mmHg}$ as estimated by the tricuspid regurgitant flow on echocardiography.

\section{Data analysis}

Survival analysis was performed using the Kaplan-Meier method, with the end points death or censoring. Patients were censored if they were still alive at last contact $(n=43)$, had received lung transplantation $(n=2)$, or died from a known cause other than CPFE $(n=2)$. The cause of death was considered to be due to CPFE when unknown $(n=4)$. Comparisons of survival were performed using the log-rank test. Values are presented as mean \pm SD unless specified otherwise. $\mathrm{p}<0.05$ was considered significant.

\section{RESULTS \\ Clinical presentation}

A total of 73 completed questionnaires were received for analysis. Twelve cases were excluded because of the presence of an associated connective tissue disease at diagnosis of the CPFE (dermatomyositis, $n=2$; rheumatoid arthritis, $n=1$; systemic sclerosis, $n=1$ ), because the $C T$ scan was not available for review $(n=7)$, or because CT diagnostic criteria were not met $(n=1)$. Sixty-one patients were included in the study. Thirty-three patients were collected in two large referral centres (L. Pradel Hospital, Lyon, 21 cases; Avicenne Hospital, Bobigny, 12 cases); each of the core authors collected $\geqslant 3$ cases; one or two cases were collected by other participants of the group (see Acknowledgements). Based on the records of the epidemiology departments, it was estimated that CPFE accounted for $\sim 5-10 \%$ of cases of idiopathic diffuse parenchymal lung disease.

All patients but one were male, and all were current or exsmokers (table 1). Ex-smokers had quit smoking for a period of

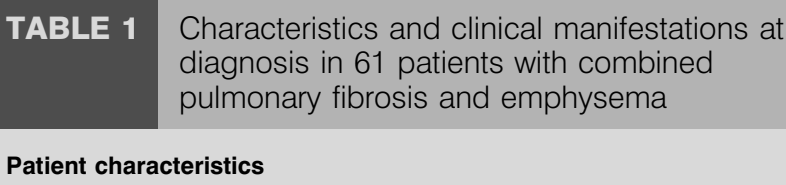
diagnosis in 61 patients with combined pulmonary fibrosis and emphysema

Patient characteristics

\begin{tabular}{lc} 
Sex M/F n & $60 / 1$ \\
Age yrs & $65.2 \pm 10.2(36-84)$ \\
Body mass index $\mathbf{~ g} \cdot \mathbf{m}^{-2}$ & $26 \pm 3(19-32)$ \\
Current/ex-/never-smokers & $19 / 42 / 0$ \\
Pack-yrs smoking & $46 \pm 27(5-120)$ \\
Current smokers & $57 \pm 27(8-120)$ \\
Ex-smokers & $41 \pm 25(5-110)$ \\
Asthenia & $14(23)$ \\
NYHA grade of dyspnoea & \\
Grade 1 & $10(16)$ \\
Grade 2 & $23(38)$ \\
Grade 3 & $23(38)$ \\
Grade 4 & $5(8)$ \\
Cough & $29(48)$ \\
Sputum production & $22(36)$ \\
Chest pain & $10(17)$ \\
Finger clubbing & $26(43)$ \\
Basal crackles & $53(87)$ \\
Wheezes & $8(13)$ \\
\hline
\end{tabular}

Data are presented as $n(\%)$ or mean \pm SD (range). M: male; F: female; NYHA: New York Heart Association. 
$10.6 \pm 10.4$ yrs. Two patients had a history of infectious pneumonia; another patient had a history of acute respiratory distress syndrome secondary to ammonia exposure. Fourteen patients $(23 \%)$ had a history of atherosclerotic coronary artery disease $(n=9)$ or atherosclerotic peripheral artery disease $(n=5)$.

The mean time between the first symptoms and diagnosis of CPFE was $2.3 \pm 4.5$ yrs (range $0-19$ yrs; median 43 days). The characteristics and clinical manifestations at diagnosis are listed in table 1 . The major clinical symptoms were dyspnoea on exertion present in all patients, and cough present in half of the patients. Finger clubbing was reported in $43 \%$ of the cases. Auscultation of the lungs found abnormalities in $90 \%$ of the patients, consisting of bilateral crackles of the lower zones of the lungs in $87 \%$, rarely associated with wheezes (13\%).

None of the patients met diagnostic criteria for pneumoconiosis, and none had significant environmental antigenic exposure.

The imaging diagnosis of emphysema preceded the identification of fibrotic changes in 16 cases with a median of 4.7 yrs (0-10.7); fibrosis was observed before emphysema in only three cases; emphysema and fibrosis were discovered concomitantly in 31 patients (no chest radiograph anterior to the diagnosis of CPFE was available in 11 cases).

\section{Biology and bronchoalveolar lavage}

The haemoglobin level was $14.9 \mathrm{~g} \cdot \mathrm{dL}^{-1} \pm 2.1$, and was $>16 \mathrm{~g} \cdot \mathrm{dL}^{-1}$ in 14 patients. The level of $\alpha_{1}$-antitrypsin was low $\left(0.19 \mathrm{~g} \cdot \mathrm{L}^{-1}\right)$ in a single patient who was PiZZ homozygous; another patient with a PiMZ phenotype had a normal level of $\alpha_{1}$-antitrypsin $\left(1.6 \mathrm{~g} \cdot \mathrm{L}^{-1}\right)$.

Bronchoalveolar lavage (BAL) was performed in 27 patients. The BAL leucocyte count was $240 \pm 200 \times 10^{6} \cdot \mathrm{L}^{-1}$ (range $71-$ $760)$. The BAL differential cell count was as follows: macrophages $76 \% \pm 24$ (range 10-90), neutrophils $10 \% \pm 19$ (2-73), eosinophils $2 \% \pm 10(0-43)$, and lymphocytes $5 \% \pm 9(0-43)$.

Antinuclear antibodies were present in 17 out of 44 patients tested $(39 \%)$, with a median titre of $1 / 160$ (range $1 / 64-1$ / 1,280 ), including 10 with a homogenous pattern and five with a speckled pattern, with anti-double-stranded DNA in none. Circulating immune complexes were found in six out of 20 cases tested, and rheumatoid factor in four out of 43 patients tested. Antineutrophil cytoplasmic antibodies were present with a low titre in four out of 35 patients tested, without antiproteinase 3 or anti-myeloperoxidase specificity on ELISA.

\section{Pulmonary function tests}

The body mass index was normal (18.5-25) in 15 patients, $>25$ in 36 patients $(60 \%)$, and $<18.5$ in none. Six-minute walk test was performed in 23 patients, including nine who were receiving oxygen during the test; the 6-min walking distance was $336 \pm 139 \mathrm{~m}$ (range 50-548), with a decrease in arterial oxygen saturation measured by pulse oximetry $\left(\mathrm{SP}, \mathrm{O}_{2}\right)$ of $9 \pm 6 \%(0-20 \%)$, and a $S \mathrm{P}, \mathrm{O}_{2}$ of $85 \pm 6 \%(74-96 \%)$ at the end of the test.

The pulmonary function parameters are listed in table 2 . Despite the presence of significant emphysematous changes on the CT scan in all patients, the mean forced expiratory volume

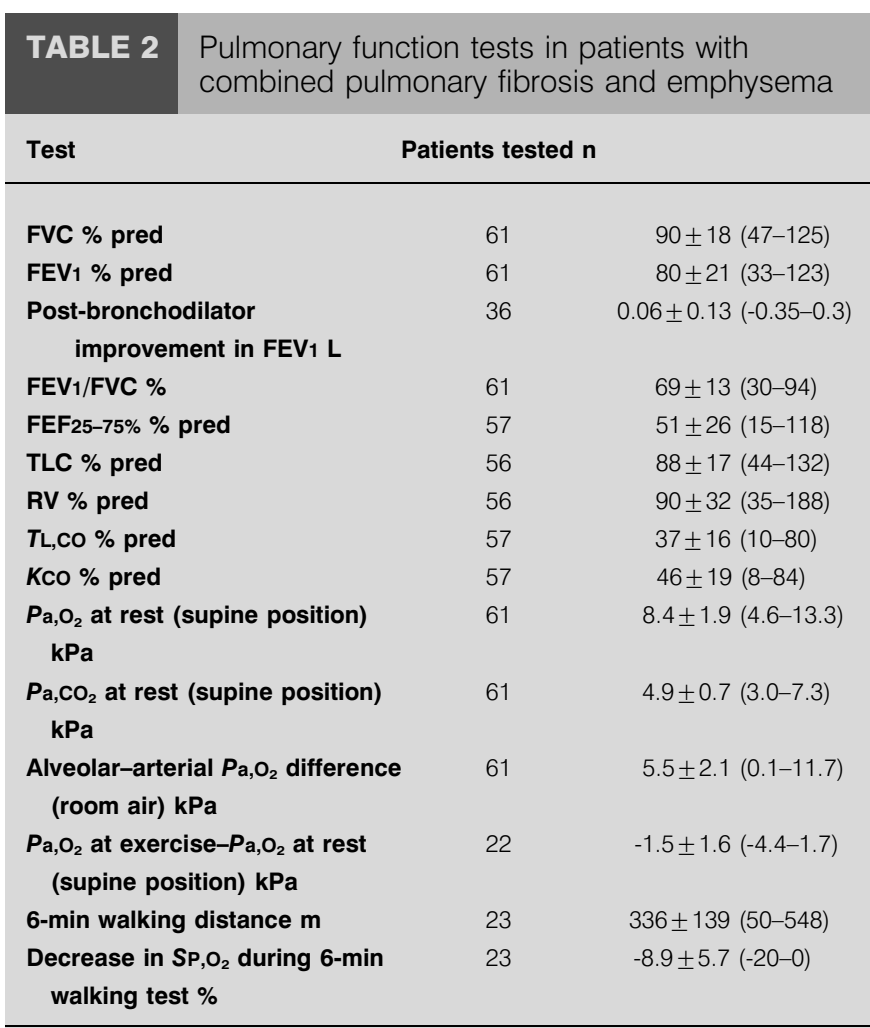

Data are presented as mean \pm SD (range), unless otherwise stated. FVC: forced vital capacity; FEV1: forced expiratory volume in one second; FEF25-75\%: mean forced expiratory flow between $25 \%$ and $75 \%$ of FVC; TLC: total lung capacity; $\mathrm{RV}$ : residual volume; $\mathrm{T} \mathrm{L}, \mathrm{CO}$ : transfer factor for carbon monoxide; $K \mathrm{CO}$ : transfer coefficient of the lung; $\mathrm{Pa}, \mathrm{O}_{2}$ : partial pressure of oxygen in arterial blood; $\mathrm{Pa}_{1} \mathrm{CO}_{2}$ : partial pressure of carbon dioxide in arterial blood; $\mathrm{SP}, \mathrm{O}_{2}$ : arterial oxygen saturation measured by pulse oximetry.

in one second (FEV1)/forced vital capacity (FVC) was 69\%, and only half of the patients (30 out of 61) presented with an obstructive ventilatory defect, as defined by FEV1/FVC $<70 \%$. The FEV 1 was $<80 \%$ of predicted ( $\%$ pred) in 29 patients $(48 \%)$, and the mean forced expiratory flow between $25 \%$ and $75 \%$ of FVC (FEF25-75\%) was $<80 \%$ in 47 out of 57 tested patients (82\%). Improvement of FEV1 upon bronchodilators was $>15 \%$ in none. A restrictive ventilatory defect as shown by decrease of total lung capacity (TLC) was found in 12 out of 56 patients $(21 \%)$. TLC $>120 \%$ pred was present in only two patients, and residual volume $>200 \%$ pred in none. Lung volumes were normal in 42 out of 56 patients (75\%). Transfer factor for carbon monoxide $(T \mathrm{~L}, \mathrm{CO})$ was $<80 \%$ pred values in 56 out of 57 tested patients $(98 \%)$, while transfer coefficient of the lung $(\mathrm{KCO})$ was $<80 \%$ pred in 54 out of 57 patients (97\%). Overall, spirometry was normal in 20 out of 61 patients (33\%), including 16 with normal TLC. A decrease of TL,CO was the only abnormal function test in 14 patients. A total of 50 patients $(82 \%)$ were hypoxaemic at rest $\left(\mathrm{Pa}, \mathrm{O}_{2}<10 \mathrm{kPa}\right)$. At exercise, $\mathrm{Pa}, \mathrm{O}_{2}$ decreased by a mean of $-1.5 \pm 1.6 \mathrm{kPa}$ and was $<10 \mathrm{kPa}$ in 18 out of 21 tested patients $(86 \%)$.

\section{Pulmonary arterial hypertension}

Forty-three patients and 49 patients had echocardiography at diagnosis and during follow-up, respectively. The prevalence 
of PAH was $47 \%$ at diagnosis, and $55 \%$ during follow-up. The mean systolic arterial pulmonary pressure was $48 \pm 19 \mathrm{mmHg}$ (range 21-96) at diagnosis and $52 \pm 20 \mathrm{mmHg}$ (range 22-96) during follow-up. PAH was confirmed by right cardiac catheterisation in six patients, with a mean arterial pulmonary pressure $\geqslant 40 \mathrm{mmHg}$ in four patients (median $40 \mathrm{mmHg}$, range $24-54)$. Eleven patients $(18 \%)$ developed right cardiac failure during follow-up.

\section{Computed tomography of the chest and pathology}

According to the inclusion criteria, CT scan of the chest showed coexistence of emphysema with upper zone predominance and parenchymal lung disease suggestive of pulmonary fibrosis of the lower lobes in all patients (fig. 1). The main findings of radiological review are summarised in table 3.

Centrilobular emphysema was present in the upper zones in all but two patients. Paraseptal emphysema was particularly frequent in this population (93\%). Bullae were seen in half of the patients.

Honeycombing, reticular intralobular opacities and traction bronchiectasis were the most frequent findings, present in 95\%, $87 \%$, and $73 \%$ of the cases, respectively. Nonprominent ground-glass attenuation was present in two-thirds of the patients. Air-space consolidation and micronodules were rare. Fibrotic changes predominated in the lower and/or middle lobe(s) in all cases, and in the subpleural areas in 56 cases (95\%). The CT pattern in the lower lobes was typical of IPF in 31 patients $(51 \%)$, strongly suggestive of IPF or fibrosing nonspecific interstitial pneumonia in 21 patients $(34 \%)$, and showed a complex pattern with predominant reticular opacities in the remaining cases.

Histological analysis of open lung biopsy or explanted lung was available for review in eight cases, and confirmed the presence of predominantly centrilobular emphysema in the upper lobes. Interstitial pneumonia was classified as usual interstitial pneumonia in five cases, desquamative interstitial pneumonia in one case, organising pneumonia in one case, and unclassifiable interstitial pneumonia in one case.

\section{Treatment and outcome}

Due to pulmonary fibrosis, half of the patients (30 out of 61) received oral corticosteroids, starting with a minimal daily dose of $0.5 \mathrm{mg} \cdot \mathrm{kg}^{-1}$ prednisone or prednisolone. Thirteen patients $(21 \%)$ received further immunosuppressive or immunomodulating agents. Fourteen patients $(23 \%)$ received long-term inhaled corticosteroids. Some improvement of the restrictive ventilatory defect was obtained with treatment in only five patients $(8 \%)$, while 11 patients remained stable clinically (18\%) and 29 deteriorated (48\%) over the follow-up period (in 16 patients the clinical outcome was not evaluable). A follow-up CT scan of the chest was available in 36 patients, showing worsening of emphysema lesions in five, worsening of fibrotic changes in 11, improvement of ground-glass opacities in two, and stable abnormalities in the remaining cases. Thirty patients $(49 \%)$ received long-term nasal oxygen therapy during follow-up, including 17 in whom oxygen therapy had to be increased during follow-up. Twenty patients $(33 \%)$ were hospitalised for acute increase of dyspnoea.
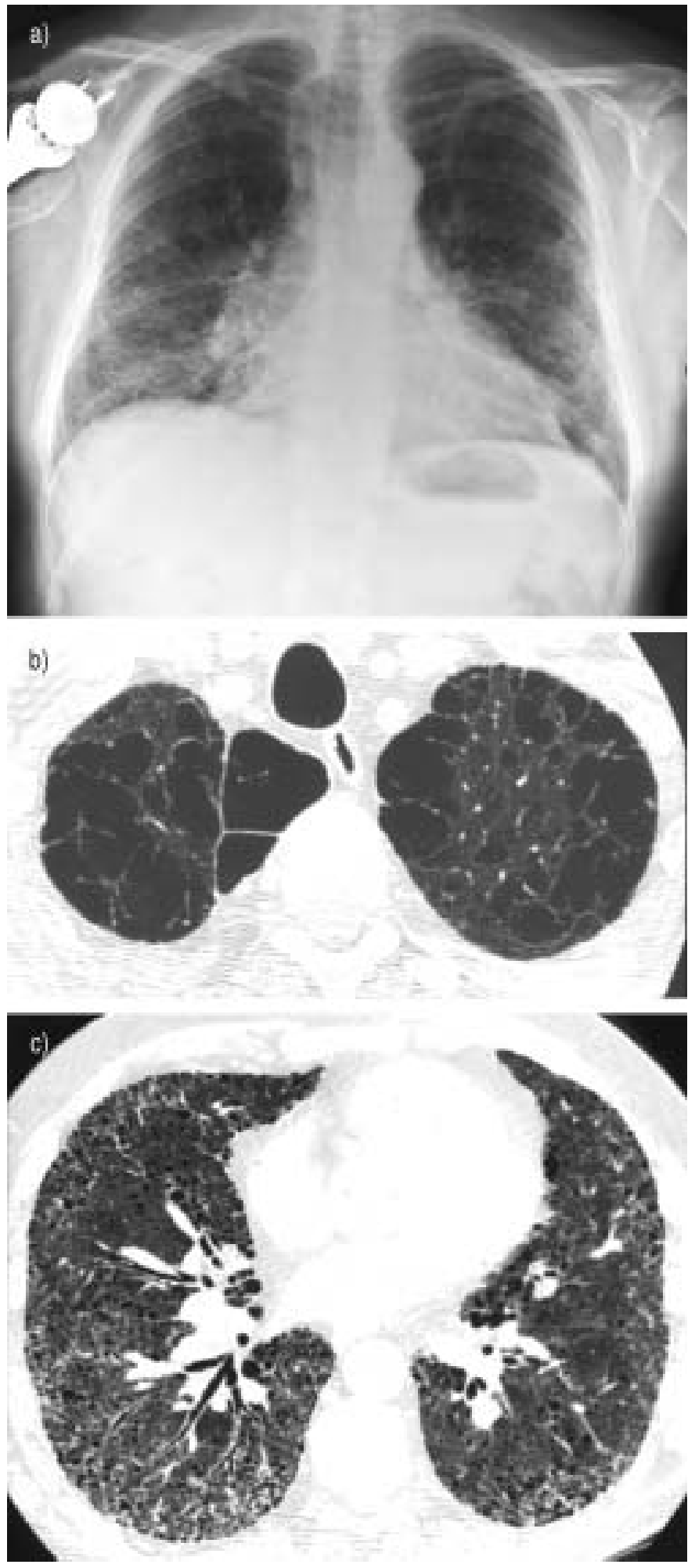

FIGURE 1. Imaging of a typical case of combined pulmonary fibrosis and emphysema. a) Chest radiograph showing bilateral infiltrative opacities of the lower lobes and hyperlucent upper zones. b) Chest computed tomography (CT) of the upper zones of the lungs showing predominant centrilobular and paraseptal emphysema. c) Chest CT of the lower zones of the lungs showing reticular opacities, honeycombing, and traction bronchiectasis. Lung biopsy performed in this patient showed centrilobular emphysema of the upper lobes and usual interstitial pneumonia of the lower lobes. 


\begin{tabular}{ll}
\hline TABLE 3 Computed tomography (CT) findings \\
\hline CT finding \\
\hline Fibrotic changes \\
$\quad$ Honeycombing \\
Reticular opacities & $58(95)$ \\
Traction bronchiectasis & $53(87)$ \\
Ground-glass opacities & $42(69)$ \\
Architectural or bronchial distortion & $40(66)$ \\
Emphysema & $24(39)$ \\
Centrilobular emphysema & \\
Paraseptal emphysema & $59(97)$ \\
Bullae & $57(93)$ \\
\hline & $33(54)$ \\
Data are presented as $n$ (\%).
\end{tabular}

The mean length of follow-up after the diagnosis was $2.1 \pm 2.8$ yrs ( $0-12$ yrs), and the total time interval from the onset of pulmonary manifestations to the last follow-up (or death) averaged $4.6 \pm 5.6 \mathrm{yrs}$ (ranging 0.2-22.2 yrs). Two patients underwent pulmonary transplantation 5.6 and 11.7 yrs after the diagnosis. Forty-seven patients were alive at the last follow-up. Fourteen patients died over that period of time, with a median time interval from diagnosis to death of 3.2 yrs. Causes of death were respiratory failure $(n=7)$, intestinal malignancy $(n=1)$, post-operative sepsis $(n=1)$, surgical complications following lung transplantation $(n=1)$, and unknown $(\mathrm{n}=4)$.

\section{Survival analysis}

Survival calculated with the Kaplan-Meier method was $91.3 \%$ at $1 \mathrm{yr}, 87.5 \%$ at $2 \mathrm{yrs}$, and $54.6 \%$ at $5 \mathrm{yrs}$, with a median survival of 6.1 yrs (fig. 2).

Clinical, radiological and functional variables were tested for influence on survival. The only statistically significant difference in survival (hazard ratio $=4.03,95 \%$ confidence interval (CI): 1.170-27.92, $\mathrm{p}=0.03$ ) was found between patients with PAH at diagnosis (median survival 3.9 yrs, 95\% CI: 1.3-6.6; mean survival 4.8 yrs, 95\% CI: 1.6-8.0; 5-yr survival 25\%) and patients without pulmonary hypertension (median survival not reached; mean survival 9.1 yrs, 95\% CI: 6.5-11.7; 5-yr survival 75\%; fig. 2). Systolic arterial pulmonary pressure correlated with KCO (Spearman rank coefficient $=0.36$; $\mathrm{p}=0.031$ ) but not with other lung function parameters (data not shown). No significant difference was observed between patients with or without PAH at diagnosis in terms of clinical, radiological and pulmonary function parameters (data not shown).

\section{DISCUSSION}

The current study provides a comprehensive analysis of a homogenous group of 61 patients with CPFE as defined by imaging criteria, leading to the individualisation of a characteristic entity. PAH at diagnosis represented a critical determinant of prognosis in these patients.

Patients were almost exclusively males. All were current or exsmokers. The median age at diagnosis (65 yrs), the prevalence
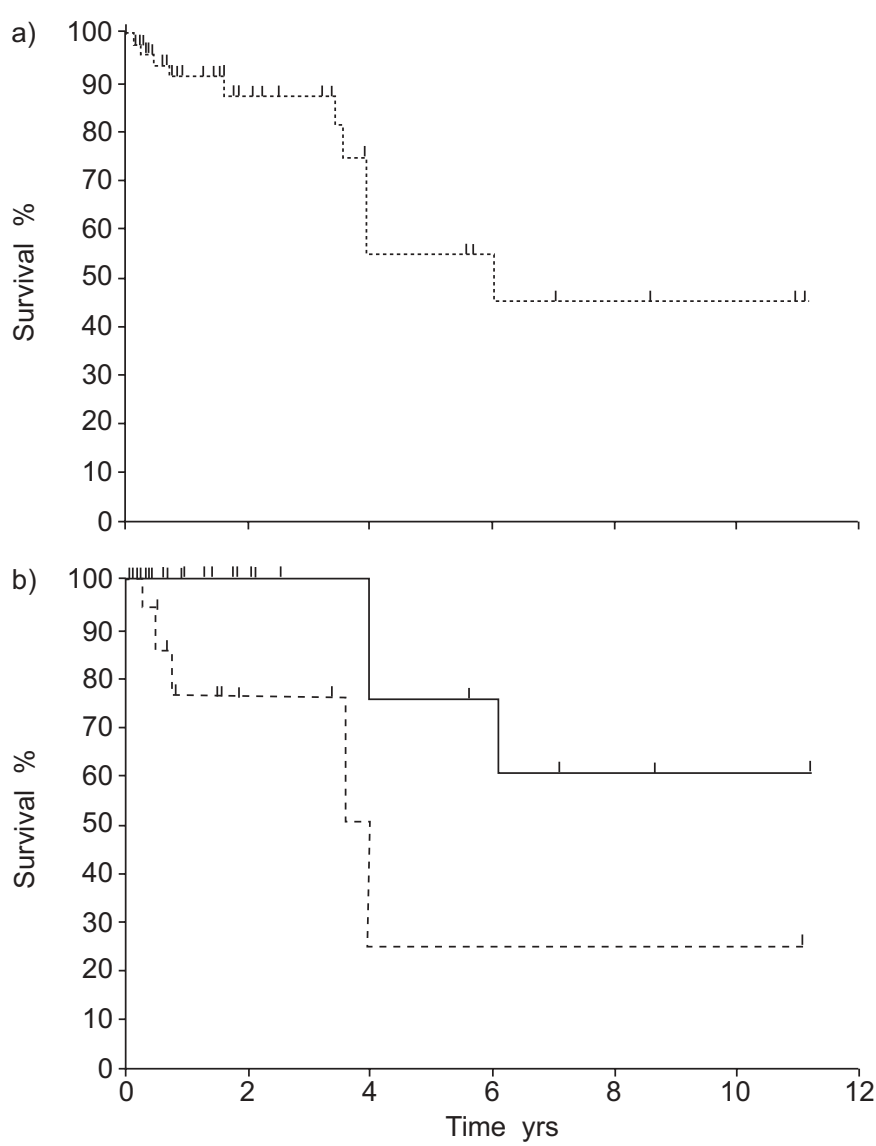

FIGURE 2. a) Survival of patients with combined emphysema and fibrosis (Kaplan-Meier analysis); 5-yr survival was 55\%. b) Kaplan-Meier analysis of survival for subjects with combined emphysema and fibrosis stratified on the basis of pulmonary arterial hypertension (PAH) at diagnosis (-: no $\mathrm{PAH}$, systolic arterial pulmonary pressure $<45 \mathrm{mmHg}$, 5-yr survival $75 \%$; ----: $\mathrm{PAH}$, systolic arterial pulmonary pressure $\geqslant 45 \mathrm{mmHg}, 5$-yr survival $25 \%$ ); $p=0.03$.

of finger clubbing (43\%), the presence of velcro-type fine inspiratory crackles predominating in the basal areas on chest auscultation in a majority of the patients, and the BAL differential cell pattern were similar to that found in IPF [7]. Nonspecific antinuclear antibodies were found in a third of the patients, although none of them had overt connective tissue disease at the diagnosis of CPFE.

Since little is known of the imaging features of CPFE, in this descriptive study, the authors chose to include patients with diffuse parenchymal lung disease suggestive of fibrosis of the lower lobes (associated with upper lobe emphysema), rather than restricting inclusion criteria to only those patients with a CT pattern typical of IPF. However, the CT pattern was that of interstitial pneumonia in all cases, with a CT pattern of IPF or fibrosing nonspecific interstitial pneumonia in $84 \%$ of the cases. The current authors suspect that the CT pattern of IPF may be altered by emphysema, so that radiological criteria for the diagnosis of IPF may not apply properly in CPFE. Since they include the evidence of restriction as a major criterion [4], the American Thoracic Society/European Respiratory Society criteria for the diagnosis of IPF in the absence of a surgical lung biopsy are not well suited for the diagnosis of idiopathic 
interstitial pneumonias when combined with emphysema. Honeycombing, reticular intralobular opacities, and traction bronchiectases were the most frequent findings. Although cases with prominent ground-glass opacities were not included according to inclusion criteria, some ground-glass opacities were present more frequently than in IPF [4], suggesting that smoking-related interstitial lung disease, such as desquamative interstitial pneumonia and respiratory bronchiolitis-interstitial pneumonia, may be present in some heavy smokers with CPFE. A histological pattern of nonspecific interstitial pneumonia may also be present in some patients with CPFE and ground-glass opacities, as reported in isolated cases [8]. The analysis of eight cases of CPFE with open lung biopsy or lung transplantation indeed showed usual interstitial pneumonia to be the predominant pattern in the lower lobes, with desquamative interstitial pneumonia in one case.

Lung function tests in patients with CPFE markedly differed from both those of patients with IPF and those of patients with emphysema. As mentioned in previous reports [1,9], the mean values of lung volumes were near normal, thus contrasting with markedly impaired capacity of carbon monoxide transfer. Measurement of FEF25-75\% may be more useful than FEV1 to detect obstructive lung disease in patients with CPFE. Hyperinflation and high compliance of the emphysematous areas of the lungs probably compensate the volume loss due to fibrosis of the lower lobes, while pulmonary emphysema and fibrosis may have additive or synergistic effects on carbon monoxide transfer and exercise hypoxaemia. Spirometry and measurement of TLC were normal in a quarter of the patients. As a consequence, CPFE may be underrecognised in patients with subnormal or normal spirometry if carbon monoxide transfer and/or exercise blood gases are not measured.

As both upper zone emphysema and lower zone fibrosis may occasionally be missed on plain chest radiographs, careful analysis of chest HRCT is warranted to accurately diagnose this syndrome. Centrilobular emphysema predominating in the upper lobes, which typically results from smoking, was the predominant radiological presentation of emphysema, while panacinar emphysema was not seen, but it is known that HRCT is inaccurate to distinguish panacinar from centrilobular emphysema [10]. A novel finding in this study is the outstanding prevalence $(>90 \%)$ of paraseptal emphysema (also called distal acinar emphysema), suggesting that it may be a hallmark of CPFE. Paraseptal emphysema is associated with tobacco smoking [11], and may by itself mimick interlobular opacities and septal lines. However, genuine infiltrative opacities suggestive of lung fibrosis were observed in the lower zones in the patients of the current study. Relationships between interstitial opacities and emphysema were variable, with emphysema lesions of the upper zones distant to fibrotic lesions of the bases in some cases, progressive transition from emphysema and fibrosis of the adjacent lung in the upper lobes to honeycomb lung in the lower lobes in other cases, and paraseptal emphysema with fibrosis-like thickening of the interlobular septa in remaining cases.

There is significant heterogeneity in survival time among patients with interstitial lung disease [4]. As estimation of prognosis may have an influence on drug treatment decisions, referral for transplantation and information given to the patient, attempts to identify indicators that reliably predict survival have become increasingly important. This study provides the first survival analysis of patients with CPFE. Median survival was $6.1 \mathrm{yrs}$, a better survival than that reported in large studies of biopsy-proven usual interstitial pneumonia which have shown a median survival of only 35 months from the time of the initial visit [12]. However, survival in CPFE was worse than that expected for emphysema in the absence of fibrosis, where an almost $100 \%$ 2-yr survival was observed in patients with FEV1 above one-third of predicted $[13,14]$, and a $19 \%$ mortality at $5 \mathrm{yrs}$ in patients with $\alpha_{1}$ antitrypsin deficiency [15]

The prevalence of pulmonary hypertension was particularly high in patients with CPFE (nearly half the patients who underwent echocardiography at diagnosis), and was higher than that reported in IPF [16-18] or chronic obstructive pulmonary disease (COPD) [19, 20], even at a late stage of the disease. In most cases, echocardiography was performed as part of routine investigations in patients with dyspnoea. However, this study being retrospective, not all patients had an echocardiography, so that the possibility that echocardiography may have been performed more often in patients with a more severe disease, and hence a higher likelihood of pulmonary hypertension, cannot be ruled out. Even assuming that patients who did not undergo echocardiography may not have pulmonary hypertension, the minimal calculated prevalence of pulmonary hypertension would still be $33 \%$ at diagnosis and $44 \%$ during follow-up. In contrast, pulmonary hypertension may have been missed by echocardiography in some cases, since the tricuspid regurgitation flow is not measurable in up to a third of patients with COPD [21] (although chest hyperinflation may not be as important in CPFE as in emphysema). This prevalence is unlikely to be due to studying patients at a particularly late stage, and rather reflects the natural history of CPFE. Pulmonary hypertension despite a rather moderate daytime hypoxaemia at rest may reflect the reduction of the capillary bed secondary to both emphysema and fibrosis (rather than the sole hypoxic pulmonary vasoconstriction), as suggested by the significant correlation between $\mathrm{KCO}$ and systolic arterial pulmonary pressure. Significantly, the presence of pulmonary hypertension at diagnosis was an independent predictor of survival. PAH has been shown to significantly affect survival in patients with COPD [20], but this has not been clearly demonstrated in patients with IPF, although evidence of pulmonary hypertension on chest radiograph has been related to a poor prognosis [12].

The pathophysiology of CPFE is unknown. A history of tobacco smoking was present in all patients, suggesting that it may be a strong determinant of the pathophysiology of this syndrome. The role of cigarette smoking is well established in emphysema [14]. Case control studies have suggested that smoking may also be a risk factor for the development of IPF [22]. In addition, tobacco smoking may alter lung function in patients in IPF [23, 24]. It has been suggested that traction of the upper zones of the lung by fibrotic lower zones may contribute to emphysema [1]. However, radiographic fibrotic changes rarely preceded the onset of emphysema, indicating 
that emphysema in CPFE did not result only from fibrotic lung retraction. It may be speculated that both emphysema and fibrosis may in some cases be related to a common environmental trigger and (or) genetic susceptibility factor, with tobacco exposure playing a central role. CPFE may thus result from the coincidental occurrence of a smoking-related interstitial lung disease in a patient with smoking-related emphysema (the latter may facilitate honeycombing in a fibrotic lung).

Therapeutic options in CPFE are limited. There was no significant benefit of corticosteroid or immunosuppressive treatment in this retrospective series. Tobacco smoking should be discontinued. Interferon- $\gamma$ is poorly effective in IPF [25], causes emphysema in mice [26], and thus is not advisable in CPFE. Specific treatments of pulmonary hypertension have not yet been evaluated in the context of pulmonary emphysema, IPF, and CPFE.

In conclusion, the syndrome of combined emphysema of the upper lobes and fibrosis of the lower lobes on chest computed tomography results in a characteristic functional profile, with preserved lung volumes, strongly impaired carbon monoxide diffusing capacity of the lung, and hypoxaemia at exercise, thus deserving the individualisation of this entity apart from both idiopathic pulmonary fibrosis and pulmonary emphysema. Despite subnormal spirometry, which may be responsible for its underrecognition, combined pulmonary fibrosis and emphysema is a severe entity. The presence of pulmonary arterial hypertension at diagnosis is a critical determinant of prognosis.

Note added to proof: since the submission of this article, pathological changes consistent with both emphysema and fibrosis have been demonstrated in transgenic mice overexpressing tumour necrosis factor- $\alpha$ [27], which may represent an experimental animal model of combined pulmonary fibrosis and emphysema.

\section{ACKNOWLEDGEMENTS}

The authors would like to thank C. Youakim, R. Frognier, J.O. Maillard, C. Compère, G. Brinchault, and S. Guillot for assistance in data collection, and S. Barrot and C. Silarakis for data entry and secretarial work. The authors would also like to thank M. Brauner (Hôpital Avicenne, Bobigny) for reviewing the CT scans, and F. Thivolet-Béjui (Hôpital L. Pradel, Lyon), M. Kambouchner (Hôpital Avicenne) and E. Brambilla (Grenoble) for pathological analysis.

The following members of the Groupe d'Etude et de Recherche sur les Maladies "Orphelines" Pulmonaires (GERM“' ${ }^{\prime \prime} \mathrm{P}$ ) participated in the study by including one or more cases: P. Carré (Carcassonne), F. Chabot (Nancy), G. Chatté (Caluire), D. Coëtmeur (Saint-Brieuc), J-F. Cordier (Lyon), V. Cottin (Lyon), I. Court-Fortune (Saint-Etienne), B. Crestani (Paris), J.C. Dalphin (Besançon), P. Delaval (Rennes), G. Devouassoux (Lyon), A. Dietemann (Strasbourg), B. Gentil (Bourgoin), M. Humbert (Paris), D. Israel-Biet (Paris), J. Lacronique (Paris), M. Mairesse (Namur, Belgium), E. Marchand (Yvoir, Belgium), H. Nunes (Bobigny), M. Reynaud-Gaubert (Marseille), I. Tillie-Leblond (Lille), and D. Valeyre (Bobigny).

\section{REFERENCES}

1 Wiggins J, Strickland B, Turner-Warwick M. Combined cryptogenic fibrosing alveolitis and emphysema: the value of high resolution computed tomography in assessment. Respir Med 1990; 84: 365-369.

2 Hiwatari N, Shimura S, Takishima T. Pulmonary emphysema followed by pulmonary fibrosis of undetermined cause. Respiration 1993; 60: 354-358.

3 Doherty MJ, Pearson MG, O'Grady EA, Pellegrini V, Calverley PM. Cryptogenic fibrosing alveolitis with preserved lung volumes. Thorax 1997; 52: 998-1002.

4 American Thoracic Society/European Respiratory Society International Multidisciplinary Consensus Classification of the Idiopathic Interstitial Pneumonias. Am J Respir Crit Care Med 2002; 165: 277-304.

5 Austin JH, Muller NL, Friedman PJ, et al. Glossary of terms for CT of the lungs: recommendations of the Nomenclature Committee of the Fleischner Society. Radiology 1996; 200: 327-331.

6 Quanjer PH, Tammeling GJ, Cotes JE, Pedersen OF, Peslin R, Yernault JC. Lung volumes and forced ventilatory flows. Report Working Party Standardization of Lung Function Tests, European Community for Steel and Coal. Official Statement of the European Respiratory Society. Eur Respir J 1993; 6: Suppl. 16, 5-40.

7 King TE Jr, Costabel U, Cordier JF, et al. Idiopathic pulmonary fibrosis: diagnosis and treatment. International consensus statement. Am J Respir Crit Care Med 2000; 161: 646-664.

8 Hansell D, Nicholson AG. Smoking-related diffuse parenchymal lung disease: HRCT-pathologic correlation. Semin Respir Crit Care Med 2003; 24: 377-391.

9 Wells AU, King AD, Rubens MB, Cramer D, du Bois RM, Hansell DM. Lone cryptogenic fibrosing alveolitis: a functional-morphologic correlation based on extent of disease on thin-section computed tomography. Am J Respir Crit Care Med 1997; 155: 1367-1375.

10 Copley SJ, Wells AU, Muller NL, et al. Thin-section CT in obstructive pulmonary disease: discriminatory value. Radiology 2002; 223: 812-819.

11 Vehmas T, Kivisaari L, Huuskonen MS, Jaakkola MS. Effects of tobacco smoking on findings in chest computed tomography among asbestos-exposed workers. Eur Respir J 2003; 21: 866-871.

12 King TE Jr, Tooze JA, Schwarz MI, Brown KR, Cherniack RM. Predicting survival in idiopathic pulmonary fibrosis: scoring system and survival model. Am J Respir Crit Care Med 2001; 164: 1171-1181.

13 Survival and FEV1 decline in individuals with severe deficiency of alpha1-antitrypsin. The Alpha-1-Antitrypsin Deficiency Registry Study Group. Am J Respir Crit Care Med 1998; 158: 49-59.

14 American Thoracic Society/European Respiratory Society Statement: Standards for the Diagnosis and Management of Individuals with Alpha-1 Antitrypsin Deficiency. Am J Respir Crit Care Med 2003; 168: 818-900.

15 Seersholm N, Dirksen A, Kok-Jensen A. Airways obstruction and two year survival in patients with severe alpha 1-antitrypsin deficiency. Eur Respir J 1994; 7: 1985-1987.

16 Jebrak G, Brugieres O, Dauriat G, Mal H, Leseche G, Fournier M. Time-course changes in pulmonary 
haemodynamics in patients with idiopathic pulmonary fibrosis (IPF) waiting for lung transplantation (LT). Eur Respir J 2004; 24: Suppl. 48, 668S.

17 Weitzenblum E, Ehrhart M, Rasaholinjanahary J, Hirth C. Pulmonary hemodynamics in idiopathic pulmonary fibrosis and other interstitial pulmonary diseases. Respiration 1983; 44: 118-127.

18 Jezek V. The prognosis and development of pulmonary hypertension in idiopathic diffuse interstitial lung fibrosis. G Ital Cardiol 1984; 14: Suppl. 1, 39-45.

19 Kessler R, Faller M, Weitzenblum E, et al. "Natural history" of pulmonary hypertension in a series of 131 patients with chronic obstructive lung disease. Am J Respir Crit Care Med 2001; 164: 219-224.

20 Weitzenblum E, Hirth C, Ducolone A, Mirhom R, Rasaholinjanahary J, Ehrhart M. Prognostic value of pulmonary artery pressure in chronic obstructive pulmonary disease. Thorax 1981; 36: 752-758.

21 Laaban JP, Diebold B, Zelinski R, Lafay M, Raffoul H, Rochemaure J. Noninvasive estimation of systolic pulmonary artery pressure using Doppler echocardiography in patients with chronic obstructive pulmonary disease. Chest 1989; 96: 1258-1262.
22 Baumgartner KB, Samet JM, Stidley CA, Colby TV, Waldron JA. Cigarette smoking: a risk factor for idiopathic pulmonary fibrosis. Am J Respir Crit Care Med 1997; 155: 242-248.

23 Schwartz DA, Merchant RK, Helmers RA, Gilbert SR, Dayton CS, Hunninghake GW. The influence of cigarette smoking on lung function in patients with idiopathic pulmonary fibrosis. Am Rev Respir Dis 1991; 144: 504-506.

24 Cherniack RM, Colby TV, Flint A, et al. Correlation of structure and function in idiopathic pulmonary fibrosis. Am J Respir Crit Care Med 1995; 151: 1180-1188.

25 Raghu G, Brown KK, Bradford WZ, et al. A placebocontrolled trial of interferon gamma- $1 \mathrm{~b}$ in patients with idiopathic pulmonary fibrosis. N Engl J Med 2004; 350: 125-133.

26 Wang $\mathrm{Z}$, Zheng $\mathrm{T}$, Zhu $\mathrm{Z}$, et al. Interferon gamma induction of pulmonary emphysema in the adult murine lung. J Clin Invest 2000; 192: 1587-1599.

27 Lundblad LK, Thompson-Figueroa J, Leclair T, et al. Tumor necrosis factor-alpha overexpression in lung disease: a single cause behind a complex phenotype. Am J Respir Crit Care Med 2005; 171: 1363-1370. 